\title{
Hyponatraemic hypertensive syndrome due to renal ischaemia: a rare presentation of Takayasu arteritis
}

\author{
*Chamila Lakmini ${ }^{1}$, Jeewana Leelarathne ${ }^{1}$, Devan Mendis ${ }^{2}$ \\ Sri Lanka Journal of Child Health, 2020; 49(4): 407-408 \\ DOI: http://dx.doi.org/10.4038/sljch.v49i4.9279 \\ (Key words: Hyponatraemic hypertensive syndrome, renin secretion, renal artery stenosis, Takayasu arteritis)
}

\section{Introduction}

Renovascular hypertension is considered to be the commonest cause of severe hypertension in children $^{1,2}$. Most of the time renal artery stenosis is idiopathic, but rarely, it can be due to underlying vasculitis. Takayasu arteritis is a rare major vessel vasculitis in children presenting with nonspecific symptoms in its acute early phase ${ }^{3}$. Delayed diagnosis due to lack of specific symptoms and laboratory criteria will lead to progressive disease resulting in fibrosis, stenosis and subsequent thrombosis involving aorta and its main branches ${ }^{3,4}$. Hyponatraemic hypertensive syndrome (HHS) is a rare condition in children that can be observed in the presence of unilateral renal ischemia secondary to excess renin secretion ${ }^{1,2,5}$. Excess renin secretion causes hypertension and diuresis and natriuresis of the contralateral healthy kidney ${ }^{1,2}$. We report an 18 month old boy with HHS secondary to unilateral renal artery stenosis due to underlying Takayasu arteritis.

\section{Case report}

An 18-month old boy with growth faltering for 4 months, presented with generalized afebrile convulsions lasting for 5 minutes. Convulsions settled with a single dose of intravenous midazolam. Subsequently, child developed haemodynamic instability requiring volume resuscitation. Despite successful volume resuscitation child was persistently drowsy with elevated blood pressure above the $95^{\text {th }}$ centile for age and sex.

${ }^{1}$ Registrar in Paediatrics,
Paediatrician, Lady Ridgeway
${ }^{2}$ Consultant
Children, Colombo, Sri Lankal for

*Correspondence: chamilk87@gmail.com
iD orcid.org/ 0000000230154161

(Received on 22 October 2019: Accepted after review on 20 December 2019)

The authors declare that there are no conflicts of interest

Personal funding was used for the project.

Open Access Article published under the Creative

Commons Attribution CC-BY (cc) (i)
On the $3^{\text {rd }}$ day, the child was progressively drowsy with a Glasgow Coma Scale (GCS) of 7 without associated respiratory compromise and generalized spasticity and hyperreflexia. Blood pressure was poorly controlled $\left(121 / 84 \mathrm{mmHg} ; 95^{\text {th }}\right.$ centile $101 / 59$ $\mathrm{mmHg}$ ) with 6 antihypertensive drugs. There was neither a blood pressure difference nor a pulse deficit (difference in a minute's time between the number of beats of the heart and the number of beats of the pulse). However, a left side renal bruit was heard.

Laboratory analysis revealed hypochloraemia (chlorine $102 \mathrm{mmol} / \mathrm{l}$ ), hyponatraemia (sodium $121 \mathrm{mmol} / \mathrm{l}$ ), hypokalaemia (potassium $2.4 \mathrm{mmol} / \mathrm{l}$ ) and polyuria. His renal function was normal. Renal ultrasound and Doppler study showed left side small kidney $(5 \mathrm{~cm} \times 1.6 \mathrm{~cm})$ with reduced flow. Hormonal profile showed very high renin level (>500 mic $\mathrm{IU} / \mathrm{ml})$ and elevated aldosterone level (1548pmol/l) with normal adrenocorticotrophic hormone (ACTH) level $(23.18 \mathrm{ng} / \mathrm{ml})$. Conventional computed tomography (CT) angiogram showed irregular mid aortic narrowing with severely stenosed left renal artery and poorly perfused small left kidney (Figures 1 and 2).

Diethylene triamine penta-acetate (DTPA) scan confirmed the poorly functioning kidney with $10.9 \%$ tracer uptake. Tuberculosis screening and inflammatory markers (erythrocyte sedimentation rate $15 \mathrm{~mm} /$ hour, C-reactive protein $5 \mathrm{mg} / \mathrm{dl}$ ) were negative. 2D echocardiography showed concentric left ventricular hypertrophy. Fundoscopy was normal.

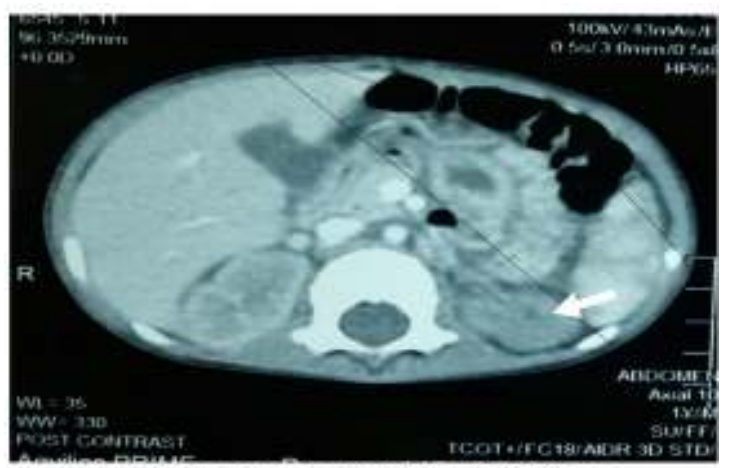

Figure 1: CT abdomen shows small left kidney 


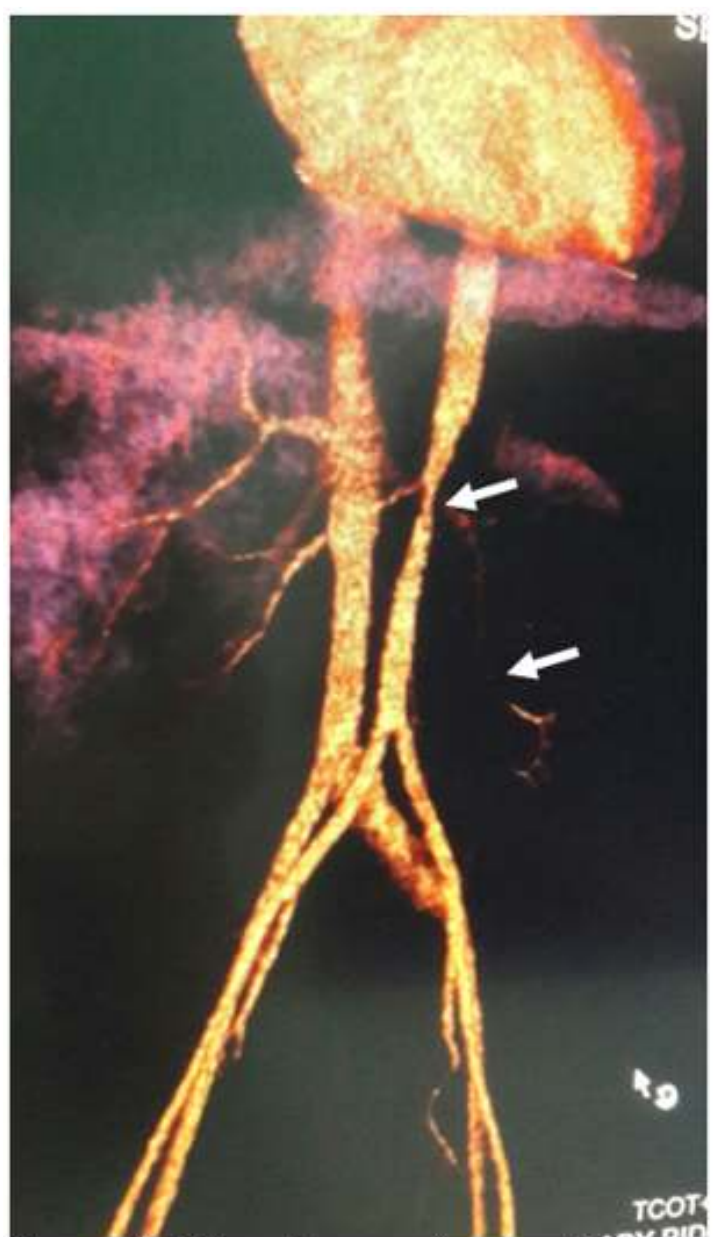

Figure 2: CT angiogram shows mid aortic narrowing and stenosed left renal artery

Corticosteroids and methotrexate were started as criteria were fulfilled for Takayasu arteritis. Following left side nephrectomy, child was discharged on day 36 on 2 antihypertensive drugs.

\section{Discussion}

HHS is a rare, underdiagnosed serious condition in children with unilateral reno-vascular disease. Here we present a child with HHS subsequently diagnosed as having left side renal ischaemia secondary to Takayasu arteritis. Unilateral renal ischaemia leads to activation of the renin aldosterone system resulting in increased renin, aldosterone and angiotensin II. Resulting hypertension, due to water retention, vasoconstriction and increased sympathetic tone, causes proteinuria, diuresis and natriuresis of the contralateral healthy kidney. Angiotensin stimulated $\mathrm{ADH}$ secretion further contributes to hyponatremia by renal retention of free water ${ }^{1,2}$. Initial management is control of hypertension with antihypertensive drugs which act on renin aldosterone system.

Takayasu arteritis is a rare large vessel vasculitis among children, with poorly defined symptoms $\mathrm{s}^{3,4}$.
Paediatric criteria for diagnosis of Takayasu arteritis have been proposed in the presence of angiographic abnormalities of aorta and its main branches ${ }^{3}$. Corticosteroids and immunosuppressants are the mainstay of management ${ }^{3,4}$. Delayed diagnosis will cause severe renal ischaemia and end organ damage (left ventricular hypertrophy, hypertensive retinopathy) secondary to hypertension. Hyponatraemia and hypertensive encephalopathy will result in irreversible neuro-disability.

\section{References}

1. Oliveira1 JC, Martins MM, Martins E, Rocha G, Moura C, Pinto H. Hyponatraemic hypertensive syndrome secondary to renal ischaemia - Case report. Journal of Pediatric and Neonatal Individualized Medicine 2018; 7(1): e070110

2. Browne WL, Nair B. The hyponatraemic hypertensive syndrome in renal artery stenosis: an infrequent cause of hyponatraemia. Journal of Postgraduate Medicine 2007; 53(1):41-3.

https://doi.org/10.4103/0022-3859.30327

PMid: 17244970

3. Brunner J, Feldman BM, Tyrrell PN, Kuemmerle-Deschner JB, Zimmerhackl LB, Gassner I, Benseler SM. Takayasu arteritis in children and adolescents. Rheumatology (Oxford) 2010; 49(10): 1806-14.

https://doi.org/10.1093/rheumatology/keq 167

PMid: 20562196

4. Aypar E, Celebi-Tayfur A, Keser M, Odabaş D, Ozaltin F, Paksoy Y, et al. Takayasu arteritis in a 4-year-old girl: case report and brief overview of the paediatric literature. Turkish Journal of Pediatrics 2012; 54(5): 536-9.

5. Siliste R, Homentcovschi C, Lanula R, Vasiliu D, Spataru D. The hyponatraemic hypertensive syndrome: When should we think about it? Journal of Hypertension 2016; 34: e259-e260. https://doi.org/10.1097/01.hjh.000049209 2.88895 .96 